\title{
A EXECUÇÃO DAS SENTENÇAS DA CORTE INTERAMERICANA DE DIREITOS HUMANOS
}

Isabela Piacentini de Andrade ${ }^{1}$

\section{RESUMO}

Artigo explicativo dos procedimentos de execução das sentenças proferidas pela Corte Interamericana de Direitos Humanos. Com ilustrações jurisprudenciais, analisa-se o inovador sistema de reparações adotado pela Corte, os fundamentos jurídicos da obrigação de executar, a competência da Corte para supervisionar a execução de suas próprias decisões, além da hipótese de execução forçada de indenizações compensatórias.

\section{ABSTRACT}

This paper aims to explain the implementation process of the judgements issued by the Inter-American Court of Human Rights. Through jurisprudence examples, it analyses the innovative Court approach regarding reparations for human rights violations, the legal basis of the obligation to comply with the decisions, the Court's function of supervising compliance with its own judgements, and the possibility to enforce compensatory damages before national tribunals.

\section{INTRODUÇÃO}

A Corte Interamericana de Direitos Humanos tornou-se uma realidade desde a entrada em vigor, em 18 de julho de 1978, da Convenção Americana de Direitos Humanos, conhecida também como Pacto de São José da Costa Rica. A Corte é o órgão jurisdicional da Organização dos Estados Americanos

\footnotetext{
${ }^{1}$ Graduada pela UFPR e mestre em direito internacional público pela Universidade de Paris II.
}

Revista Brasileira de Direito Internacional, Curitiba, v.3, n.3, jan./jun.2006 
(OEA), e sua função é julgar as violações ao Pacto ${ }^{2}$. Apenas os países que reconheceram a competência obrigatória da Corte podem ser julgados ${ }^{3}$, e desde que o caso tenha passado previamente pela Comissão Interamericana de Direitos Humanos, órgão encarregado de promover o respeito e a defesa dos direitos e liberdades previstos no Pacto de São José.

A submissão de um caso à Corte é uma faculdade reservada à Comissão e aos Estados-partes da Convenção que aceitaram a jurisdição contenciosa da Corte. Os indivíduos não são dotados de legitimidade processual ativa. O particular pode, no entanto, ter acesso de forma indireta ao sistema interamericano ao dirigir suas reclamações à Comissão, a qual poderá acionar a Corte posteriormente. Em 2001, foi igualmente permitida aos indivíduos (supostas vítimas, seus familiares ou representantes) a participação no processo. Eles podem apresentar petições, argumentos e provas, mesmo não sendo formalmente partes. ${ }^{4}$

Findo o processo, a Corte profere uma sentença fundamentada, definitiva e inapelável que é obrigatória para o Estado condenado ${ }^{5}$. A execução das decisões da Corte é o objeto deste estudo. Iniciamos pela análise do conteúdo reparatório das sentenças interamericanas, já que nele se encontram as medidas a serem executadas pelo Estado condenado. Em seguida, trataremos do dever de executar, decorrente da natureza obrigatória das sentenças e da responsabilidade internacional do Estado. E por fim, estudaremos a execução das sentenças propriamente dita, a qual pode se dar de forma espontânea ou forçada.

\footnotetext{
2 A Corte possui também uma função consultiva, podendo emitir pareceres sobre a interpretação da Convenção Americana e de outros tratados concernentes à proteção dos direitos humanos nos Estados americanos (art. 64).

${ }^{3}$ O Brasil aceitou a competência obrigatória da Corte pelo Decreto Legislativo n. 89 (1998) e Decreto n. 4463 (2002).

${ }_{4}^{4}$ Artigo 23 do Regulamento da Corte Interamericana de Direitos Humanos (em vigor a partir de $1^{\circ}$. de junho de 2001).

${ }^{5}$ Arts. 66 a 68 da Convenção Americana.
}

Revista Brasileira de Direito Internacional, Curitiba, v.3, n.3, jan./jun.2006 


\section{AS REPARAÇÕES NO SISTEMA INTERAMERICANO}

O artigo $63 \quad \S 1$ do Pacto de São José dispõe que a Corte Interamericana ordenará, uma vez constatada uma violação aos seus dispositivos, que seja garantido ao prejudicado o gozo dos direitos ou liberdades infringidos. Ela ordenará igualmente, se for o caso, a reparação das conseqüências da medida ou situação que causou a violação destes direitos, bem como o pagamento de uma indenização justa à parte lesada.

Esse artigo confere à Corte Interamericana o poder de decidir quais as formas de reparação cabíveis para remediar uma violação que tenha sido constatada. A Corte faz uma interpretação ampla do que é o dever de reparar, baseando-se no direito da responsabilidade internacional dos Estados: "ao produzir-se um fato ilícito imputável a um Estado, surge a responsabilidade internacional deste pela violação de uma norma internacional. Em razão desta responsabilidade nasce para o Estado uma relação jurídica nova que consiste na obrigação de reparar." ${ }^{\prime 6}$ Conseqüentemente, toda transgressão aos direitos fundamentais previstos no Pacto que causem danos gera um dever de reparação adequada. Segundo a doutrina internacionalista, a reparação contempla três modalidades principais: a restituição, a indenização e a satisfação. A primeira delas busca a volta ao estado anterior, de forma a apagar as conseqüências do ato ilícito como se ele nunca tivesse existido. Esta naturalis restitutio ou restitutio in integrum repara o dano da forma mais satisfatória, porém nem sempre pode ser concretizada, pois a reconstrução da situação prévia à violação é às vezes impossível. Passa-se então às formas alternativas de reparação: através da indenização, os danos materiais e morais podem ser convertidos em um montante pecuniário que visa a compensar a vítima; pela satisfação, busca-se sobretudo um conforto moral e o reconhecimento do erro cometido pelo Estado, que pode por exemplo reconhecer publicamente sua falta ou homenagear as vítimas de alguma

\footnotetext{
${ }^{6}$ Caso Baena Ricardo y otros vs. Panamá. Competencia. Sentença de 28 nov. 2003, § 65; Caso Garrido y Baigorria. Reparaciones. Sentença de 27 ago. 1998, entre outros. (tradução livre do espanhol). Disponível em: www.corteidh.or.cr.
}

Revista Brasileira de Direito Internacional, Curitiba, v.3, n.3, jan./jun.2006 
forma. ${ }^{7}$ A própria sentença, na medida em que declara a ilicitude da conduta estatal, constitui em si uma forma de satisfação.

Exemplo dessa diversidade de espécies reparatórias é o Caso "19 comerciantes vs. Colômbia, relativo à detenção, desaparecimento e execução de 19 comerciantes por um grupo paramilitar agindo sob o comando do exército colombiano. Após ter declarado que a Colômbia havia violado várias disposições da Convenção Americana, a Corte ordenou a esse Estado, entre outros: (i) a investigação dos crimes em questão e o julgamento dos responsáveis, (ii) a procura dos restos mortais dos assassinados para entregálos às famílias, (iii) a construção de um monumento em homenagem às vítimas, (iv) a realização de um ato público no qual o Estado deveria reconhecer sua responsabilidade internacional em relação aos crimes cometidos, (iv) a concessão gratuita de um tratamento médico e psicológico aos familiares das vítimas, e (v) o pagamento de indenizações pecuniárias por danos materiais e morais. $^{8}$

No caso acima e na maioria dos casos que foram submetidos à Corte, a restitutio in integrum afigurou-se inatingível pois as vítimas já estavam falecidas, cabendo apenas a reparação do dano de forma alternativa. A primeira vez em que se pôde visar à restituição foi o célebre caso Loyaza Tamayo vs. Peru. María Elena Loyaza Tamayo foi presa, torturada e condenada irregularmente pelo Estado peruano pelo delito de terrorismo. A Corte constatou que o Peru havia violado vários dispositivos da Convenção, como aqueles sobre o direito à liberdade pessoal, à integridade física e às garantias judiciais. Com a vítima ainda viva seria possível estabelecer o estado anterior à violação, o que a Corte procurou fazer de maneira exemplar. A libertação de María Elena, ordenada pela sentença, não seria suficiente para que se restabelecesse in integrum sua situação anterior. Foi-se portanto mais além e surgiu o conceito de "projeto de vida", o qual "atiende a la realización integral de la persona afectada, considerando su vocación, aptitudes,

\footnotetext{
${ }^{7}$ V. COMBACAU, Jean e SUR, Serge. Droit international public, $6^{a}$. ed. Paris: Montchrestien, 2004, p. 523-524.

${ }^{8}$ Caso « 19 Comerciantes "Vs. Colombia, Resolucion de la Corte Interamericana de Derechos Humanos de 2 febrero de 2006 (cumplimiento de sentencia). Disponível em: www.corteidh.or.cr.
}

Revista Brasileira de Direito Internacional, Curitiba, v.3, n.3, jan./jun.2006 
circunstancias, potencialidades y aspiraciones, que le permiten fijarse razonablemente determinadas expectativas y acceder a ellas. ${ }^{, \theta}$ Nessa linha, a Corte ordenou ao Peru as seguintes medidas de reparação-restituição: a reincorporação da vítima ao serviço docente público, a garantia à Loyaza do pleno gozo do seu direito à jubilação, e a adoção de medidas para assegurar que nenhuma resolução que tenha sido emitida no processo civil ao qual a vítima foi submetida produza efeito legal. ${ }^{10} \mathrm{~A}$ decisão da Corte contemplou igualmente outras formas de reparação, como a fixação de indenizações, a obrigação de investigar os fatos e sancionar os responsáveis, e de modificar a legislação peruana de maneira a conformá-la à Convenção Americana.

Assim, quando a Corte constata uma violação, ela determina também a forma de reparação mais apropriada. Além disso, ela especifica ao Estado quais as medidas concretas que ele deve tomar para remediar o ilícito cometido. Nesse particular, o juiz americano é muito mais intrusivo que o europeu nas ordens jurídicas estatais. A Corte Européia de Direitos do Homem "decide se uma disposição da Convenção [européia] foi ou não violada no caso em questão, sem dizer o que seria conveniente fazer para remediar tal violação e prevenir outras da mesma natureza (...) o Estado demandado é livre para escolher os meios pelos quais ele cumprirá sua obrigação legal (...)"11. Os Estados europeus têm uma grande autonomia, podendo resolver como agir para remediar o ilícito constatado. A discricionaridade dos Estados americanos é ao contrário restrita, pois as sentenças da Corte da Costa Rica detalham as medidas que o país deve tomar, deixando-lhe pouca margem de manobra.

Além dos casos já citados, exemplos de decisões audaciosas da Corte Interamericana não faltam. No caso Barrios Altos v. Peru, a Corte chega a declarar que duas leis peruanas de anistia carecem de efeitos jurídicos, pois incompatíveis com a Convenção. ${ }^{12}$ No caso Olmedo Bustos y otros vs. Chile (caso "La Ultima Tentación de Cristo"), o Chile foi instado a modificar sua

\footnotetext{
${ }^{9}$ Caso Loyaza Tamayo vs. Peru. Reparaciones. Sentença de 27 nov. 1998, § 147.

${ }^{10}$ Idem, § 192.

${ }^{11}$ Avis sur la mise en oeuvre des arrêts de la Cour européenne des droits de l'homme (adopté par la Commission de Venise lors de sa 53ème session plénière). Veneza, 13-14 de dezembro de 2002, p. 10, parágrafos 34 e 36.

${ }^{12}$ Caso Barrios Altos vs. Perú. Sentença de 14 mar. 2001, §44.
}

Revista Brasileira de Direito Internacional, Curitiba, v.3, n.3, jan./jun.2006 
constituição a fim de reformar um dispositivo que limitava a liberdade de expressão. ${ }^{13} \mathrm{~A}$ decisão proferida no caso Castillo Petruzzi y otros vs. Peru declarou inválido o processo penal que condenou irregulamente as vítimas pelo delito de traição da pátria, ordenando um novo julgamento com plena observância do devido processo legal. ${ }^{14}$

A Corte exerce portanto um papel ativo na execução de suas próprias decisões, pois ordena as medidas individuais e gerais que os Estados devem observar para reparar as violações praticadas. Cabe ao país condenado, todavia, a escolha dos órgãos ou autoridades internas que tomarão as ações necessárias para executar a sentença, tal atribuição podendo recair sobre o poder executivo, legislativo ou judiciário.

\section{A OBRIGAÇÃO DE EXECUTAR AS SENTENÇAS DA CORTE}

O artigo $68 \S 1$ da Convenção Americana dispõe que os Estados signatários comprometem-se a cumprir as decisões da Corte em todo caso em que forem partes. Tal é o fundamento convencional da natureza obrigatória das sentenças interamericanas. Mas além desse artigo, a Corte invoca igualmente o direito internacional como base jurídica do caráter vinculante de seus julgados. Repetidas vezes, a Corte afirma que a obrigação de executar é um princípio fundamental do direito da responsabilidade internacional do Estado, princípio esse que reza que o Estado deve cumprir de boa fé as obrigações que assumiu convencionalmente (pacta sunt servanda), não podendo alegar motivos internos como recusa. ${ }^{15}$

\footnotetext{
${ }^{13}$ Caso "La Última tentación de Cristo" (Olmedo Bustos vs. Chile), sentença de 5 fev. 2001. Disponível em www.corteidh.or.cr.

${ }_{14}$ Caso Castillo Petruzzi y otros, sentença de 30 mai. 1999. Disponível em www.corteidh.or.cr.

${ }^{15}$ Ver por exemplo os casos Barrios Altos v. Peru (resolução de 27 nov. 2002), Castillo Paez v. Peru (res. de 27 nov. 2002), Loyaza Tamayo v. Peru (res. de 27 nov. 2002), Blake v. Guatemala (res. de 27 nov. 2002), Caballero Delgado v. Peru (res. de 27 nov. 2002), Durand e Ugarte v. Peru (res. de 27 nov. 2002), El Amparo v. Venezuela (res. de 27 nov. 2002), Neira Alegria e alii v. Peru (res. de 27 nov. 2002) e Baena Ricardo et alii v. Panamá (res. de 22 nov. 2002 e de 6 jun. 2003).
}

Revista Brasileira de Direito Internacional, Curitiba, v.3, n.3, jan./jun.2006 


\section{Quando da execução da sentença proferida no caso Castillo Petruzzi y} otros v. Peru ${ }^{16}$ supracitado, o Estado peruano declarou que esta decisão internacional era inexecutável, pois violava a sua soberania e sua Constituição. Em resposta, a Corte Interamericana sublinhou o caráter obrigatório da sentença (artigo 68 §1) e afirmou, evocando o princípio do pacta sunt servanda e o artigo 27 da Convenção de Viena sobre o Direito dos Tratados, que o Estado não pode alegar razões de ordem interna para se furtar a assumir sua responsabilidade internacional e respeitar seus compromissos convencionais.

A Corte também sublinha constantemente que o Estado tem o dever de tomar todas as medidas necessárias para dar efeito e executar corretamente suas sentenças. Isso decorre da obrigação geral dos signatários da Convenção de não apenas respeitá-la, mas igualmente de agir para tornar efetivos os direitos e liberdades nela previstos. ${ }^{17}$ Assim,

\footnotetext{
"los Estados Partes en la Convención deben garantizar el cumplimiento de las disposiciones convencionales y sus effectos propios (effet utile) en el plano de sus respectivos derechos internos. Este principio se aplica no sólo en relación con normas sustantivas de los tratados de derechos humanos (es decir, las que contienen disposiciones sobre los derechos protegidos), sino también en relación con las normas procesales, tales como las que se refieren al cumplimiento de las decisiones de la Corte (artículos 67 y 68.1 de la Convención). Las disposiciones contenidas en los mencionados artículos deben ser interpretadas y aplicadas de manera que la garantía protegida sea verdaderamente práctica y eficaz, teniendo presentes el caráter especial de los tratados de derechos humanos y su implementación colectiva." ${ }^{18}$
}

16 Caso Castillo Petruzzi y otros (cumplimiento de sentencia). Resolucion de la Corte Interamericana de Derechos Humanos de 17 noviembre de 1999, série $\mathrm{C} \mathrm{n}^{\circ} 59$. Disponível em: www.corteidh.or.cr.

${ }^{17}$ V. CANÇADO TRINDADE, Antônio Augusto. La Convention américaine relative aux droits de I'homme et le droit international général. In: COHEN-JONATHAN, G. e FLAUSS, J-F. Droit international, droits de l'homme et juridictions internationales. Bruxelas: Bruylant, 2004, p. 68; CANÇADO TRINDADE, A.A. O sistema interamericano de direitos humanos no limiar do novo século: recomendações para o fortalecimento de seu mecanismo de proteção. In: GOMES, Luiz Flávio e PIOVESAN, Flávia. O sistema interamericano de proteção dos direitos humanos e o direito brasileiro. São Paulo: RT, 2000, p. 134.

${ }_{18}$ Caso Baena Ricardo y otros vs. Panamá, cit., § 66; Caso del Tribunal Constitucional. Competencia. Sentença de 24 set. 1999, § 36; Caso Ivcher Bronstein. Competencia. Sentença de 24 set. 1999, § 37. Disponíveis em: www.corteidh.or.cr.

Revista Brasileira de Direito Internacional, Curitiba, v.3, n.3, jan./jun.2006 
Para CANÇADO TRINDADE, se os Estados deixam de cumprir a obrigação de executar prevista pelo artigo $68 \S 1$, eles incorrem em uma nova violação do Pacto, além da(s) violação(ões) já apontada(s) pela sentença. ${ }^{19}$

\section{A EXECUÇÃO DAS SENTENÇAS}

\subsection{A SUPERVISÃO DO CUMPRIMENTO DAS SENTENÇAS PELA} CORTE

A Corte se encarrega ela própria da verificação do cumprimento de seus julgados. Ela supervisiona as medidas adotadas pelos Estados até a total observância das obrigações estipuladas, não encerrando o caso até então. Vincula-se, dessa forma, a cessação do ilícito à execução integral da sentença. É preciso que o Estado esteja conforme à Convenção, sua obrigação primária. Enquanto o Estado não cumpre totalmente a sentença, a violação convencional persiste.

O caso Baena Ricardo y otros v. Panamá é rico de ensinamentos sobre o fundamento da competência da Corte para supervisionar a execução de suas próprias sentenças:

\footnotetext{
"La Corte, como todo órgano con funciones jurisdiccionales, tiene el poder inherente a sus atribuciones de determinar el alcance de su propia competencia (compétence de la compétencel Kompetenz-Kompetenz). Los instrumentos de aceptación de la cláusula facultativa de la jurisdicción obligatoria (artículo 62.1 de la Convención) presuponen la admisión, por los Estados que la presentan, del derecho de la Corte de resolver cualquier controversia relativa a su jurisdicción, como lo es en este caso la función de supervisión del cumplimiento de sus sentencias. Una objeción o cualquier otra actuación del Estado realizada con el propósito de afectar la competencia de la Corte es inocua, pues en cualesquiera circunstancias la Corte retiene la 'compétence de la compétence', por ser maestra de su jurisdicción". 20

"Una vez determinada la responsabilidad internacional del Estado por la violación de la Convención Americana, la Corte procede a ordenar las medidas destinadas a reparar dicha violación. La jurisdicción comprende la faculdad de administrar justicia; no se limita a declarar el derecho, sino que también comprende la supervisión del cumplimiento de lo juzgado. Es por
}

${ }^{19}$ CANÇADO TRINDADE, A.A. Las cláusulas pétreas de la protección internacional del ser humano. In: El Sistema Interamericano de Protección de los Derechos Humanos en el Umbral del Siglo XXI, 2a . ed. São José: Corte Interamericana de Derechos Humanos, 2003, p. 60.

${ }^{20}$ Caso Baena Ricardo, cit., $§ 68$.

Revista Brasileira de Direito Internacional, Curitiba, v.3, n.3, jan./jun.2006 
ello necesario establecer y poner en funcionamiento mecanismos o procedimientos para la supervisión del cumplimiento de las decisiones judiciales, actividad que es inherente a la función jurisdiccional. La supervisión del cumplimiento de las sentencias es uno de los elementos que componen la jurisdicción. Sostener lo contrario significaría afirmar que las sentencias emitidas por la Corte son meramente declarativas y no efectivas. El cumplimiento de las reparaciones ordenadas por el Tribunal en sus decisiones es la materialización de la justicia para el caso concreto y, por ende, de la jurisdicción; en caso contrario se estaría atentando contra la 'raison d'être' de la operación del Tribunal.",21

A Corte vela pela implementação de seus julgamentos através do exame de informações submetidas pelo Estado condenado e pela vítima ou seus representantes sobre as ações estatais adotadas. Com base nesses dados, a Corte emite resoluções que indicam quais as obrigações que já foram cumpridas integral e corretamente e quais são aquelas faltantes. Não são raros os casos em que as medidas tomadas pelo Estado são insuficientes ou ineficazes para satisfazer a obrigação prescrita. A Corte é persistente nessa escrupulosa tarefa de exame, motivo pelo qual para cada sentença são emitidas normalmente várias resoluções até que o cumprimento pleno seja constatado. Algumas das obrigações ditadas na decisão requerem ações trabalhosas e demoradas, fazendo com que o número de execuções sob verificação da Corte aumente a cada ano. Segundo seu último Informe Anual (2005), 59 era o número de sentenças supervisionadas. ${ }^{22}$

$\mathrm{Na}$ hipótese de inexecução dos julgados, a Convenção prevê o envolvimento de um órgão político, a Assembléia Geral da OEA. Segundo o artigo 65 do Pacto de São José, a Corte deve submeter anualmente um relatório de suas atividades à Assembléia, e "de maneira especial, e com as recomendações pertinentes, indicará os casos em que um Estado não tenha dado cumprimento a suas sentenças". É o que prevê igualmente o artigo 30 do Estatuto da Corte.

Mas tal alternativa quase não foi utilizada até o momento. A Corte quis empregar pela primeira vez esse procedimento para pressionar Honduras a respeitar as sentenças proferidas nos casos Velasquez Rodriguez e Godinez Cruz, mas sem sucesso. Honduras havia pago as indenizações fixadas nos

\footnotetext{
${ }^{21}$ Idem, $\S 72$.

${ }^{22}$ Contra 42 em 2004, 32 em 2003, 27 em 2002... ver p. 73 do Informe Anual 2005 da Corte. Disponível em www.corteidh.or.cr.
}

Revista Brasileira de Direito Internacional, Curitiba, v.3, n.3, jan./jun.2006 
julgados, mas se negava a pagar os juros que a Corte impôs pelo fato de 0 pagamento ter sido efetuado em atraso. A Corte havia preparado uma resolução detalhada apontando o descumprimento de Honduras, a qual deveria ser apresentada no seu relatório anual à Assembléia Geral. Entretanto, devido a fortes pressões exercidas por este país, a informação nunca foi apresentada oficialmente. Apesar disso, Honduras acabou pagando o que devia algum tempo depois. ${ }^{23}$ Mais recentemente, a Corte denunciou o Equador à Assembléia pelo descumprimento de uma das obrigações ordenada pela sentença do caso Benavides Cevallos: investigar, julgar e sancionar os responsáveis pelas violações de direitos humanos cometidas contra a vítima. ${ }^{24}$ Segundo o último Informe Anual (2005), a sentença encontra-se ainda pendente de cumprimento. ${ }^{25}$

Em 29 de junho de 2005, a Corte promulgou uma Resolução na qual ela estipula que, a partir do momento em que se decida pela denúncia do Estado faltoso à Assembléia, não se continuará a solicitar-lhe informações sobre o cumprimento da sentença. Se o Estado não apresentar posteriormente comprovação da observância das questões em aberto, a Corte continuará a incluí-lo a cada ano no seu Informe à Assembléia Geral.

O objetivo da exposição do Estado faltoso diante da Assembléia é o de exercer pressão política, já que os esforços de supervisão da Corte se mostraram insuficientes. Infelizmente, a ausência de meios coercitivos para executar as sentenças internacionais faz com que a única maneira de pressionar o Estado seja causar-Ihe constrangimentos diante dos seus pares da comunidade internacional. Em última análise, portanto, poderíamos afirmar que a execução de decisões internacionais se faz de maneira espontânea, devido à ausência de meios coativos para sujeitar o Estado. Isso não significa que a sentença não seja obrigatória. Como explicado acima, todos os signatários da Convenção obrigaram-se internacionalmente a executar os

\footnotetext{
${ }^{23}$ PASQUALUCCI, J. M. The Practice and Procedure of the Inter-American Court of Human Rights. Cambridge: Cambridge University Press, 2003, p. 288-289.

${ }^{24}$ Caso Benavides Cevallos vs. Ecuador. Cumplimento de Sentencia. Resolución de 27 noviembre de 2003. V. também Informe Anual de la Corte Interamericana de Derechos Humanos 2003, p. 44-45. Disponíveis em: www.corteidh.or.cr.

${ }^{25}$ Informe Anual da Corte 2005, p. 46. Disponível em: www.corteidh.or.cr.
}

Revista Brasileira de Direito Internacional, Curitiba, v.3, n.3, jan./jun.2006 
acórdãos da Corte, sob pena de responsabilização internacional. Entretanto a execução forçada não é possível pois a Corte não dispõe de aparato coercitivo para tanto. Cabe ao Estado respeitar voluntariamente os compromissos que assumiu. Existe uma única possibilidade de executar coercitivamente as sentenças da Corte: o caso em que se determina o pagamento de uma indenização. Nesta hipótese, que analisaremos a seguir, a vítima ou seus representantes podem obter uma execução forçada, mas a coerção não virá do sistema internacional, mas dos próprios meios estatais.

\subsection{A EXECUÇÃO DAS INDENIZAÇÕES COMPENSATÓRIAS}

Como vimos, a execução das obrigações estipuladas pelos julgados da Corte são normalmente espontâneas, salvo quando se concedeu uma indenização. Para estes casos, a Convenção previu um tratamento especial. Segundo seu artigo 68 §2, as indenizações podem ser executadas na ordem interna do país condenado consoante os procedimentos nacionais previstos para a execução de decisões proferidas contra o Estado. Assim, em se tratando de uma indenização, duas são as formas possíveis de execução: a execução espontânea do Estado e a execução forçada diante das jurisdições nacionais, sob iniciativa do particular beneficiário.

A parte da sentença que fixa uma indenização constitui, pois, título executivo nas ordens internas ${ }^{26}$. Tal norma não tem similar no sistema europeu, representando uma importante alternativa para as vítimas, as quais poderão materializar ao menos a parte pecuniária da sentença se o Estado recusar-se a cumpri-la. $\mathrm{O}$ aparato coercitivo do Estado é assim colocado à disposição da vítima, constituindo seu último remédio.

Mas a ausência de precedentes suscita dúvidas quanto à aplicação prática desse dispositivo.

\footnotetext{
26 V. CÁRCOMO LOBO, Maria Teresa. Execução de decisões juridiciais de Cortes Internacionais contra Estados soberanos. Série Cadernos do CEJ, vol. 23, 2003, p. 406. Disponível em http://www.cjf.gov.br/revista/seriecadernos/vol23/artigo17.pdf. Acesso em 30 nov. 2006; MAZZUOLI, Valério de Oliveira. As Sentenças Proferidas por Tribunais Internacionais Devem ser Homologadas pelo Supremo Tribunal Federal?, p. 3. Disponível em: http://www.juspodivm.com.br/novodireitocivil/ARTIGOS/convidados/att0369.pdf. Acesso em 30 nov. 2006.
}

Revista Brasileira de Direito Internacional, Curitiba, v.3, n.3, jan./jun.2006 
BUERGENTHAL questiona, por exemplo, se a parte beneficiária da indenização poderá demandar a execução perante as jurisdições nacionais, já que ela não foi parte no processo diante da Corte. É uma questão formal, mas que pode suscitar alegações de ilegitimidade ou falta de interesse processual. ${ }^{27}$

Outro ponto que suscita alguma discussão doutrinária é a necessidade de homologação da sentença interamericana pelo STJ ${ }^{28}$. Seria ela uma sentença estrangeira sujeita a tais controles internos? MAZZUOLI, CÁRCOMO LOBO e MAIA E PÁDUA respondem negativamente a essa questão. Para eles, uma sentença internacional distingue-se claramente de uma sentença estrangeira e não deve portanto ser submetida aos mesmos procedimentos homologatórios. A decisão estrangeira foi proferida por uma jurisdição estranha ao país, o que justifica a necessidade de controle. O julgado internacional, diferentemente, provém de um tribunal que exerce jurisdição sobre o Estado, ao qual este aderiu espontaneamente e de cujo processo participou como parte. É insensato sustentar que o país pode eximir-se de uma obrigação assumida internacionalmente devido a uma decisão interna que nega a homologação. ${ }^{29}$

Assunto que será igualmente fonte de problemas práticos é a forma de pagamento da indenização estabelecida pela Corte. A questão se coloca para as duas hipóteses de execução: espontaneamente pelo Estado ou coercitivamente sob iniciativa do beneficiário. Embora alguns autores brasileiros entendam que o pagamento deve ser feito através de precatórios ${ }^{30}$, já que este é o procedimento previsto pelo nosso direito interno, tal via extremamente morosa não é a mais adequada para o cumprimento das sentenças interamericanas. Como sustenta MAIA E PÁDUA, "é evidente que,

\footnotetext{
${ }^{27}$ BUERGENTHAL, Thomas. Implementation of the Judgements of the Court. In: El Sistema Interamericano de Protección de los Derechos Humanos en el Umbral del Siglo XXI, $2^{\mathrm{a}}$. ed. São José: Corte Interamericana de Derechos Humanos, 2003, p. 188-189.

${ }_{28}$ A partir da Emenda Constitucional 45/2004, cabe ao STJ - e não mais ao STF - a homologação de sentenças estrangeiras (artigo 105, I, i da Constituição Federal).

${ }^{29}$ V. CARCOMO LOBO, op. cit., p. 408 e MAZZUOLI, op. cit.

${ }^{30}$ v. MAZZUOLI, op. cit. MAIA E PÁDUA, Antônio de. Supervisão e cumprimento das sentenças interamericanas. Cuestiones Constitucionales, n. 15, julio-diciembre 2006, p. 188. Disponível em: http://www.ejournal.unam.mx/cuestiones/cconst15/CUC1507.pdf. Acesso em 30 nov. 2006. CÁRCOMO LOBO o admite indiretamente, ao aventar a hipótese de pagamento sem a necessidade de submissão a precatório em caso de indenização de natureza alimentar (op. cit., p. 407).
}

Revista Brasileira de Direito Internacional, Curitiba, v.3, n.3, jan./jun.2006 
mesmo sendo a Corte uma autoridade judicial, suas decisões não estão submetidas ao regime do precatório. Cogitar o contrário, além de ser perda de tempo, contraria a lógica daquele sistema de pagamento que se contrapõe à penhora, mecanismo completamente desconhecido pela jurisdição internacional. ${ }^{31} \mathrm{O}$ autor sugere que se trate o pagamento da indenização como ato administrativo, sendo responsabilidade da União, pois foi a República que se obrigou internacionalmente. $O$ ideal seria conceber previamente um procedimento interno específico de execução das sentenças interamericanas. Caso contrário, diante de má vontade estatal, as vítimas ficarão à mercê da morosidade do judiciário e do sistema de precatórios.

Não houve ainda nenhum caso no Brasil de execução de montante pecuniário fixado pela Corte. Mas situação similar foi a indenização versada a José Pereira Ferreira, baseada em um procedimento oriundo não da Corte, mas da Comissão Interamericana. $\mathrm{O}$ caso era de um trabalhador submetido à escravidão numa fazenda do Pará; o Estado brasileiro teria violado a Convenção por ter permitido tal prática, sendo omisso ou cúmplice. Reconhecendo sua responsabilidade internacional, o Brasil pagou uma indenização de $R \$ 52.000,00$ à vítima a título de danos materiais e morais. $O$ pagamento foi autorizado pela lei 10.706 de 30 de julho de 2003, e efetuado através de uma ordem bancária menos de um mês depois. ${ }^{32}$ Evidentemente nesse caso o Brasil deu uma resposta rápida e eficaz ao problema, evitando a burocracia interna que indubitavelmente faria a vítima aguardar ainda muitos anos para receber sua indenização.

Este caso no entanto resultou de uma solução amistosa atingida no âmbito da Comissão, e não da Corte. Todas as atenções devem se voltar agora para o primeiro caso de condenação do Brasil por esta jurisdição, o caso Ximenes Lopes. Damião Ximenes Lopes, cidadão que sofria de distúrbios mentais, foi torturado e morreu na Clínica de Repouso Guararapes, instituição psiquiátrica cearense sob supervisão e fiscalização do poder público brasileiro

\footnotetext{
${ }^{31}$ Op. cit., p. 12.

${ }^{32}$ V. Informe n. 95/03, Petición 11.289, Solución Amistosa José Pereira, Brasil, 24 oct. 2003. Disponível

em: http://www.oas.org/main/main.asp?sLang=P\&sLink=http://www.oas.org/documents/por/structur e.asp. Acesso em 30 nov. 2006.
}

Revista Brasileira de Direito Internacional, Curitiba, v.3, n.3, jan.jun.2006 
(Sistema Único de Saúde - SUS). A sentença da Corte, proferida em 4 de julho de 2006, declarou que o Estado brasileiro violou disposições do Pacto de São José relativas à integridade pessoal e ao direito à vida em relação a Damião, além da violação de direitos às garantias judiciais e proteção judicial em relação a seus familiares. ${ }^{33}$

A decisão determinou, entre outros, a investigação e punição dos responsáveis pelas lesões e morte de Damião, e o desenvolvimento pelo governo brasileiro de um programa de capacitação e formação de pessoas vinculadas ao atendimento de saúde mental. Fixou também indenizações a serem versadas aos familiares da vítima: US\$11,5 mil a título de danos materiais, e US $\$ 125$ mil a título de danos morais. Foi concedido o prazo de um ano para pagamento. Para cumpri-lo, o Brasil terá que adotar um procedimento veloz e evitar os trâmites burocráticos tradicionais.

Em caso de descumprimento, os beneficiários poderão recorrer à execução forçada por meios internos. Requerendo a execução do seu título executivo pelas vias jurisdicionais, entretanto, será difícil imaginar que o juiz inove o direito nacional e determine o pagamento de forma diversa do lento sistema de precatórios. Esperamos que não seja necessário chegar a essa última alternativa e que o Brasil, consciente de suas obrigações internacionais, cumpra espontânea e integralmente a sentença da Corte.

\section{CONCLUSÃO}

O sistema de execução das sentenças da Corte Interamericana nos parece exemplar. Nossos primeiros elogios vão para a ousada e inovadora jurisprudência desta Corte em matéria de reparações. Indo além do que se poderia esperar de um tribunal internacional, ela utiliza de forma hábil e corajosa as instituições de direito das gentes para responsabilizar os Estados por violações de direitos humanos.

Em segundo lugar, louvável é a trabalhosa mas salutar iniciativa da Corte de supervisionar a execução das próprias decisões. Ouvindo os dois

${ }^{33}$ Caso Ximenes Lopes vs. Brasil. Sentença de 4 de julho de 2006. Disponível em: www.corteidh.or.cr.

Revista Brasileira de Direito Internacional, Curitiba, v.3, n.3, jan./jun.2006 
lados, e dando publicidade aos fatos, a Corte expõe o Estado não somente perante seus pares, mas também da sociedade civil internacional. Essa forma de pressão moral afigura-se eficaz, pois raros são os casos em que a Corte teve que recorrer à Assembléia Geral da OEA para se servir da sua pressão política.

E por fim, resta-nos aplaudir o feliz dispositivo da Convenção Americana que prevê o recurso às jurisdições internas para a execução de indenizações compensatórias. Embora ainda não possamos discorrer sobre sua utilização prática, parece-nos que a existência dessa alternativa conferirá maior efetividade às decisões.

Obviamente, o sistema interamericano não é perfeito. A acesso do indivíduo à jurisdição ainda é um passo importante que temos que dar, seguindo o exemplo europeu. Mas não cabe à Corte, e sim aos Estados membros da OEA, dar esse passo, através de uma modificação convencional. Cabe igualmente aos países contribuir para a eficácia do sistema que eles mesmo conceberam. Temos certeza de que muitos deles o fazem, nutrindo nobres metas em termos humanitários. Outros, infelizmente, a despeito dos belos discursos, ignoram e desrespeitam vergonhosamente os direitos humanos. Guantánamo é o exemplo vivo desse ultraje. Não é por acaso que os Estados Unidos nunca aceitaram a competência da Corte, já que eles nem são parte da Convenção Americana. No nosso ponto de vista, a Corte tem feito seu melhor nesses 27 anos de atuação, mas um avanço humanitário significativo no continente americano só será possível se os Estados fizerem sua parte.

\section{REFERÊNCIAS}

BUERGENTHAL, Thomas. Implementation of the Judgements of the Court. In: El Sistema Interamericano de Protección de los Derechos Humanos en el Umbral del Siglo XXI, $2^{a}$. ed. São José: Corte Interamericana de Derechos Humanos, 2003, p. 185-193.

CANÇADO TRINDADE, Antônio Augusto. La Convention américaine relative aux droits de l'homme et le droit international général. In: COHEN-JONATHAN, G. e FLAUSS, J-F. Droit international, droits de l'homme et juridictions internationales. Bruxelas: Bruylant, 2004, p. 54-71. 
CANÇADO TRINDADE, A.A. Las cláusulas pétreas de la protección internacional del ser humano. In: El Sistema Interamericano de Protección de los Derechos Humanos en el Umbral del Siglo XXI, ${ }^{a}$. ed. São José: Corte Interamericana de Derechos Humanos, 2003, p. 5-68.

CÁRCOMO LOBO, Maria Teresa. Execução de decisões juridiciais de Cortes Internacionais contra Estados soberanos. Série Cadernos do CEJ, vol. 23, 2003. Disponível em http://www.cjf.gov.br/revista/seriecadernos/vol23/artigo17.pdf. Acesso em 30 nov. 2006.

COMBACAU, Jean e SUR, Serge. Droit international public, $6^{a}$. ed. Paris: Montchrestien, 2004.

GOMES, Luiz Flávio e PIOVESAN, Flávia. O sistema interamericano de proteção dos direitos humanos e o direito brasileiro. São Paulo: RT, 2000.

MAIA E PÁDUA, Antônio de. Supervisão e cumprimento das sentenças interamericanas. Cuestiones Constitucionales, n. 15, jul-dez 2006, p. 177-192. Disponível em: http://www.ejournal.unam.mx/cuestiones/cconst15/CUC1507.pdf. Acesso em 30 nov. 2006.

MAZZUOLI, Valério de Oliveira. As Sentenças Proferidas por Tribunais Internacionais Devem ser Homologadas pelo Supremo Tribunal Federal? Disponível em:

http://www.juspodivm.com.br/novodireitocivil/ARTIGOS/convidados/att0369.pdf. Acesso em 30 nov. 2006.

PASQUALUCCI, J. M. The Practice and Procedure of the Inter-American Court of Human Rights. Cambridge: Cambridge University Press, 2003.

Revista Brasileira de Direito Internacional, Curitiba, v.3, n.3, jan./jun.2006 